\title{
Entendimento e engajamento dos usuários de saúde sobre o Conselho Municipal de Saúde: um relato de experiência
}

Knowledge and engagement of health user's about the Municipal Health Council: an experience report

Comprensión y participación de los usuarios de la salud sobre el Consejo Municipal de Salud: un relato de experiência

\begin{abstract}
Resumo
A Saúde Pública brasileira foi constituída a partir de inúmeros fatores históricos e contou com a participação popular para sua consolidação, processo esse que abriu espaços para manifestação popular e institucionalização do Sistema Único de Saúde (SUS). Esses espaços, após a institucionalização do SUS, são denominados órgãos de controle social, estão dispostos em lei e possuem grande importância para o desenvolvimento de políticas públicas que atendam às necessidades de saúde de pessoas, famílias e comunidade. O presente artigo objetiva compreender o engajamento e entendimento de pessoas residentes em um município do interior do Rio Grande do Sul sobre o Conselho Municipal de Saúde (CMS) local. Trata-se de um estudo qualitativo, descritivo, em que foi realizado um relato de experiências referente a atividade sobre controle social realizada em uma disciplina de Saúde Coletiva, a partir da qual duas estudantes dos cursos de Psicologia e Fisioterapia elaboraram uma enquete para consultar a população sobre seus conhecimentos acerca do órgão. A enquete foi elaborada através de uma plataforma Google e aplicada com usuários do SUS no mês de dezembro de 2020. Os resultados apontam que a população não conhece de fato o CMS e, consequentemente, não exerce efetivamente os seus direitos. Entende-se que a participação social é um processo, relativamente, recente na história do País e que está em processo de construção. No entanto, para que a popularização do controle social ocorra é necessário despender esforços, informar a população e incentivar a sua participação.
\end{abstract}

Palavras-chave: Saúde pública; Conselhos de saúde; Participação pública; Sistema Único de Saúde.

\begin{abstract}
The brazilian public health was constituted from countless historical factors and counted with the popular participation for its consolidation, a process that opened spaces for popular manifestation on the Unified Health System (SUS) management. These spaces are called social control organs, are laid out in law and have a big importance for the development of public policy that attend to the real needs of citizens. The present article aims to understand the engagement and knowledge of people residing in a city in Rio Grande do Sul about the local Municipal Health Council (CMS). It is a qualitative study, descriptive, in which it was made an experience report referent an activity about social control realized in a Public Health class, from which two student from the courses of psychology and physiotherapy elaborated a survey to consult the population about their knowledge about the organ. The survey was made in a Google platform and applied with SUS users in december 2020. The results point that the population, in fact, do not know the CMS and, consequently, does not effectively exercise its rights. It is understood that the social participation is a relatively recent process in the history of the country and it is in construction process. However, for the popularization of social control to occur, it is necessary to expend efforts, inform the population and encourage their participation.
\end{abstract}

Keywords: Public health; Health councils; Community participation; Unified Health System. 


\begin{abstract}
Resumen
La Salud Pública Brasileña se constituyó a partir de innumerables factores históricos y contó con la participación popular para su consolidación, proceso que abrió espacios para la manifestación popular y la institucionalización del Sistema Único de Saúde (SUS). Esos espacios, tras la institucionalización del SUS, son denominados órganos de control social, están dispuestos en ley y poseen gran importancia para el desarrollo de políticas públicas que atiendan a las necesidades de salud de personas, familias y comunidad. Este artículo busca comprender el compromiso y el entendimiento de personas residentes en un municipio del interior de Rio Grande do Sul acerca del Consejo Municipal de Salud (CMS) local. Se trata de un estudio cualitativo y descriptivo, en que fue realizado un relato de experiencias referente a la actividad sobre control social realizada en una disciplina de Salud Colectiva, a partir de la cual dos estudiantes de Psicología y Fisioterapia elaboraron una encuesta para consultar la población sobre sus conocimientos acerca del órgano. La encuesta fue elaborada a través de una plataforma Google y aplicada con usuarios del SUS en diciembre de 2020. Los resultados apuntan que la población no conoce de hecho el CMS y, consecuentemente, no ejerce efectivamente sus derechos. Se entiende que la participación social es un proceso relativamente reciente en la historia del país y que está en fase de construcción. Sin embargo, para que la popularización del control social ocurra es necesario invertir esfuerzos, informar a la población e incentivar su participación.
\end{abstract}

Palabras clave: Salud pública; Consejos de salud; Participación de la comunidad; Sistema Único de Salud.

\title{
1. Introdução
}

A Saúde Pública no Brasil foi construída baseada em diversos pilares históricos que a trouxeram até a realidade atual. Passando pela chegada dos imigrantes ao Brasil, o período colonial, a época do império, as campanhas de vacinação de Oswaldo Cruz, os avanços da era Vargas, precariedades no saneamento básico, a ascensão da medicina privada, a subnotificação do regime militar e os movimentos sociais (Bertolli Filho, 2011).

No ano de 1941, ocorreu a Primeira Conferência Nacional de Saúde, com a participação de autoridades e profissionais do Ministério dos Negócios da Educação e Saúde Pública. Na ocasião discutiu-se, entre outros assuntos, a organização de um programa nacional de saúde e a administração sanitária e assistencial dos estados e municípios (Brasil, 2014).

Em 1953, o Programa Nacional de Saúde e a Administração Sanitária e Assistencial dos Estados e Municípios, até então conduzido pelo Ministério dos Negócios da Educação e Saúde Pública passou a ser administrado pelo denominado Ministério da Saúde, marcando início o estabelecimento de uma Política Nacional de Saúde (Brasil, 2014). No entanto, a verba destinada à saúde ao longo da década era ínfima e impedia a atuação eficaz do Estado na manutenção da saúde coletiva (Bertolli Filho, 2011), doenças infecciosas seguiam prevalentes no país, bem como às taxas de mortalidade e morbidade (Brasil, 2014).

Em 1964, instaurou-se o Regime Militar no país, período em ocorreram inúmeras transformações políticas, “abertura da economia ao capital estrangeiro, desarticulação da participação social” (Paiva \& Teixeira, 2014, p. 17). No campo da saúde, tinha-se um sistema dividido entre a saúde privada, dirigida principalmente aos cuidados individuais de trabalhadores urbanos com Carteira de Trabalho assinada; e a saúde pública, direcionada principalmente às ações de prevenção com a população rural e setores mais pobres (Paiva \& Teixeira, 2014). Como estratégia, a saúde

(...) passou a ter como foco, de um lado, a medicalização da sociedade e a incorporação das modificações tecnológicas vindas do exterior, e, de outro, a estratégia sanitarista tradicional. Predominava no cenário a medicina previdenciária, com seus braços privados, enquanto a saúde pública assumia caráter marginal (Brasil, 2014, p. 21).

Ao longo do período investiu-se em transporte e segurança, ao passo que a saúde pública recebia cada vez menos recursos (Paiva \& Teixeira, 2014).

Com a crise econômica internacional, o crescimento econômico do país também entrou em declínio no fim da década de 1970. Isso acabou estimulando o aumento de tensões sociais (Paiva \& Teixeira, 2014) e a emersão de movimentos políticos e sociais, entre eles, o Movimento Sanitarista (Albuquerque, 2015). 
O Movimento Sanitário propunha a unificação do sistema de saúde, ampliação das ações sanitárias, incorporação de práticas integrais e equitativas e também “à garantia de participação permanente da sociedade na gestão como um todo do sistema de saúde" (Brasil, 2014, p. 23). Segundo Bertolli Filho (2011, p. 63):

Um dos principais produtos desse movimento foi a elaboração de um documento intitulado Pelo direito universal à saúde [grifo do autor], que sublinha a necessidade de o Estado se comprometer definitivamente com a assistência à saúde da população. Nesse texto afirma-se com ênfase que o acesso à assistência médico-sanitária é direito do cidadão e dever do Estado [grifo do autor].

Com a redemocratização do país em 1985 e o início da Nova República, as demandas sociais começaram a ter respostas e os temas emergidos anteriormente passaram a compor o que se chamou de Reforma Sanitária Brasileira, marcada pela $8^{\text {a }}$ Conferência Nacional de Saúde (CNS) (Brasil, 2014). Considerada um marco histórico para o país, a Conferência realizada em março de 1986 contou, com a participação de mais de quatro mil pessoas (Brasil, 1986), entre elas, pela primeira vez, estiveram presentes representantes da sociedade civil.

O debate teve como tema central a "Saúde como direito, reformulação do Sistema Nacional de Saúde e financiamento do setor" (Brasil, 2014). Conforme aponta o relatório da $8^{\mathrm{a}} \mathrm{CNS}$, após a assembleia ficou claro que, além de reformas administrativas e financeiras, era necessário ampliar o conceito de saúde e rever a legislação no que se refere à promoção, proteção e recuperação da saúde (Brasil, 1986).

Com a soma de pequenos avanços, no dia 19 de setembro de 1990, foi deferida a Lei n. 8.080 que "dispõe sobre as condições para promoção, proteção e recuperação da saúde, a organização e o funcionamento dos serviços correspondentes e dá outras providências" (Lei n. 8.080, de 19 de setembro de 1990). A lei é responsável por regulamentar o Sistema Único de Saúde (SUS), além de apresentar suas diretrizes, que são a universalidade, integralidade, equidade, descentralização, hierarquização, regionalização e controle social. Esse último item, o controle social, diz respeito à participação popular na tomada de decisões e fiscalização (Brasil, 2005).

Com o objetivo de regulamentar a participação social, a Lei n. 8.142 foi aprovada em 28 de dezembro de 1990 e “dispõe sobre a participação da comunidade na gestão do Sistema Único de Saúde (SUS) e sobre as transferências intergovernamentais de recursos financeiros na área da saúde e dá outras providências" (Lei n. 8.142, de 28 de dezembro de 1990). Essa lei determina que cada nível de governo irá contar com o Conselho de Saúde,

(...) órgão colegiado composto por representantes do governo, prestadores de serviço, profissionais de saúde e usuários, atua na formulação de estratégias e no controle da execução da política de saúde na instância correspondente, inclusive nos aspectos econômicos e financeiros, cujas decisões serão homologadas pelo chefe do poder legalmente constituído em cada esfera do governo (Lei n. 8.142, de 28 de dezembro de 1990, texto digital).

Ainda sobre a lei de 28 de dezembro de 1990, foram determinadas as Conferências de Saúde, que apesar de já existirem anteriormente, agora passam a fazer parte da legislação, sendo realizadas em âmbito municipal, estadual e federal, a cada quatro anos, diferentemente dos Conselhos de Saúde, que são órgãos permanentes (Lei n. 8.142, de 28 de dezembro de 1990).

Os conselhos e conferências são constituídos por atores sociais, ou seja, indivíduos ou grupos de indivíduos que participam ativamente da gestão da saúde pública, bem como de sua organização e planejamento (Brasil, 2005). Sobre a composição dos Conselhos, determina-se que 50\% deles sejam usuários do Sistema de Saúde e, a outra metade, representantes de outros segmentos da sociedade, sendo reservadas $25 \%$ das vagas para profissionais da saúde e outros $25 \%$ para representantes do governo e prestadores de serviços (Brasil, 2014). 
Observando a história da Saúde Pública no Brasil, percebe-se a importância que a participação social teve para a aquisição e garantia de direitos. O controle social foi uma conquista histórica fundamental para o desenvolvimento do SUS (Brasil, 2014). Nesse sentido, entende-se que:

Os conselhos de saúde e as conferências de saúde se constituem, atualmente, nos principais espaços para o exercício da participação e do controle social na implantação e na implementação das políticas de saúde em todas as esferas de governo (Brasil, 2014, p. 14).

Diante disso, as autoras desenvolveram o presente estudo, que surgiu a partir de discussões realizadas ao longo das aulas do componente curricular Saúde Coletiva, vinculado à área de Ciências da Vida da Universidade do Vale do Taquari Univates. Ao relatar a experiência de discussões do componente curricular e resultados de uma enquete realizada com parte da população de um município do Vale do Taquari - RS, objetiva-se compreender o engajamento e entendimento da população do município analisado com o CMS local. Acredita-se que este estudo possa possibilitar uma reflexão sobre os direitos e deveres que envolvem o controle social, contribuir com a literatura científica e estimular a conscientização política no meio acadêmico.

\section{Metodologia}

Trata-se de um estudo qualitativo, descritivo, tipo relato de experiência referente a atividade sobre controle social desenvolvida em um município de pequeno porte, localizado no Vale do Taquari, interior do Rio Grande do Sul. A ação foi realizada por acadêmicas dos cursos de Psicologia e Fisioterapia no mês de dezembro de 2020, a partir da disciplina de Saúde Coletiva, da Univates. Esta disciplina possui abordagem interdisciplinar e é de caráter obrigatório para todos os cursos da área da saúde da Universidade em questão.

Durante uma das aulas do componente curricular supracitado, discutiu-se a respeito dos órgãos de controle social e a participação da população no CMS, discussão essa que impulsionou as estudantes, autoras deste estudo, a investigarem mais sobre o conhecimento da população acerca do órgão e escreverem sobre o assunto, como atividade extracurricular. Foi desta forma que se manifestou a ideia de elaboração de uma enquete a ser aplicada com usuários do SUS residentes em um município do interior do Rio Grande do Sul. O presente estudo, portanto, utiliza como base o relato de experiência do conteúdo estudado e discutido em sala de aula, além dos resultados do formulário elaborado pelas acadêmicas. Todo o estudo contou com a orientação da professora ministrante do componente curricular.

A enquete foi elaborada através de uma plataforma Google e enviada para os contatos das redes sociais das autoras de forma aleatória. Primeiramente, apresentou-se o trabalho a ser desenvolvido e seus objetivos, após solicitou-se o consentimento do participante a partir do próprio formulário, com sua confirmação, levantou-se questões para entender o contexto em que ele está inserido. Por fim, questionou-se acerca do CMS, buscando entender qual o nível de entendimento e engajamento do respondente sobre o órgão.

O questionário foi organizado com perguntas fechadas e abertas, as primeiras tinham como objetivo compreender um pouco mais sobre o participante questionando-o quanto a cidade de residência, área de atuação/estudo ligada, ou não, a área da saúde e uma pergunta inicial para verificar se o respondente já havia ouvido falar do CMS até aquele momento. A partir da resposta nessa última questão, o participante era direcionado para as perguntas abertas, onde solicitava-se para explicar o que, no seu entendimento, é o CMS e, em caso de já ter participado de alguma reunião, compartilhar sua experiência. Os dados foram analisados a partir do método qualitativo, cruzando-se às respostas dadas pelos participantes e a interpretação dos dados por parte das autoras. A escolha do método se deu, pois, conforme Turato (p. 509, 2005) o método qualitativo busca compreender o "significado individual ou coletivo para a vida das pessoas", nesse estudo o objetivo não é entender o que é o 
CMS, mas sim compreender o entendimento e engajamento das pessoas sobre ele.

Ao longo das questões, não foram realizadas perguntas pessoais e não se exigiu identificação, respeitando-se os princípios éticos. Conforme fundamentado por Pereira et al. (2018) o método de pesquisa através de questionário possui essa vantagem de realizar uma investigação anônima e sem influência de opiniões do entrevistador nas respostas.

Além do caráter investigativo da enquete, em função dos resultados encontrados que coadunam com a hipótese inicial do estudo - "o desconhecimento da população sobre o órgão de controle social CMS" - também se realizou uma ação informativa com os participantes, sendo anexada uma cartilha ao final do questionário, contendo informações básicas sobre o CMS e incentivando a população a participar.

Quanto aos procedimentos éticos, na etapa inicial da aplicação do questionário aos usuários, antes de qualquer questão, disponibilizou-se um Termo de Consentimento Livre Esclarecido, solicitando-se, logo abaixo, o consentimento, ou não, do participante. Caso houvesse discordância, a participação era encerrada sem quaisquer prejuízos.

\section{Resultados e Discussão}

O formulário desenvolvido contou com a participação de 44 pessoas, sendo que quatro delas foram excluídas por não residirem no município cenário do estudo. Dos quarenta participantes, quatro eram estudantes ou profissionais da área da saúde e 36 não tinham qualquer relação profissional ou acadêmica com esta área.

Em relação aos estudantes ou profissionais da saúde (quatro), dois conheciam o CMS e conseguiram definir com precisão a função desse órgão colegiado, enquanto dois desconheciam o assunto. Um dos participantes ainda apontou que conhecia o CMS graças à faculdade, quando, em semestres anteriores, fez uma disciplina de Saúde Coletiva.

Com relação aos participantes que não estavam ligados à área da saúde (36), 17 afirmaram conhecer, ou já ter ouvido falar a respeito do CMS e 19 afirmaram não ter conhecimento sobre o assunto. Quando os participantes, que afirmaram ter ouvido falar do Conselho, foram questionados sobre seu conhecimento acerca do órgão, três afirmaram não saber do que se trata, apenas teriam ouvido falar. Os demais que apontaram conhecer o CMS conceituaram o órgão de forma superficial, sem muito aprofundamento. Entre os relatos dos participantes pôde-se notar que eles confundiram funções similares entre a Secretaria Municipal de Saúde e o CMS.

Para aqueles que afirmavam conhecer o CMS (19), incluindo estudantes e profissionais da saúde e os que não são da área, apenas um afirmou já ter participado de uma das reuniões periódicas desse órgão colegiado. Segundo o participante, a experiência foi um pouco decepcionante tendo em vista a expectativa ter sido frustrada, em função de ter ficado com a impressão que os presentes estavam ali apenas por obrigação.

O questionamento aos participantes sobre o motivo da não participação nas reuniões do CMS fomentou uma série de argumentações, como a ausência de interesse, convite, ligação profissional com a área da saúde e, sobretudo, informações precisas sobre como participar.

Nas discussões realizadas em sala de aula, percebeu-se que, em outros municípios da região, a participação dos usuários em reuniões do Conselho também tende a ser baixa, ou quase inexistente, com exceção de um município com campus universitário. A falta de divulgação dos horários e locais das reuniões também foi relatada por diversos estudantes, além de não terem conhecimento sobre quem são os conselheiros ou como podem entrar em contato com o conselho.

Observando os resultados do questionário, percebe-se que, além das falhas de divulgação dos dias, horários e locais das reuniões, há um desconhecimento da população quanto à existência do CMS e as suas funções. Assim, um ponto que se pode concluir é que o CMS não funciona na prática da mesma forma que é apresentado na teoria, a partir da legislação, que idealiza esse órgão como um processo de democratização da participação social na situação de saúde do município. Para 
Rolim, Cruz e Sampaio (2013, p. 145), "é preciso que o controle social aconteça na prática, para que não fique apenas em lei e que a sociedade civil ocupe de modo pleno e efetivo esses diversos espaços de participação social".

Cotta, Cazal e Martins (2010, p. 2441) apontam algumas irregularidades na composição do Conselho e afirmam que "através destas regularidades organizacionais, pretende-se colocar em questão o grau de democratização interno das organizações de saúde, que demarca o fluxo do processo decisório e o grau de influência de cada instância ou unidade de organização na gestão institucional”.

Comparando os resultados do presente estudo com as análises feitas na pesquisa por Cotta, Martins, Batista, Franceschinni, Priore e Mendes (2011), pode-se notar que muitos resultados se assemelham: a maioria dos conselheiros não sabem sua real função dentro do Conselho, além de terem relatado que foram nomeados para participar, mas não sabem o motivo. Nesse sentido, observa-se que falta conhecimento tanto da população em geral, como dos integrantes do conselho, fazendo com que o órgão não funcione como deve ser.

Outra reflexão apontada é que "em muitos municípios, as diretrizes essenciais para a garantia da atuação destes como um espaço para o exercício concreto do controle social em saúde não são respeitadas" (Cotta et al., 2011, p. 1130) e acaba que o CMS só existe porque é obrigatória a sua existência para que o município receba verba do SUS. Uma forma de melhorar o funcionamento do CMS é divulgar mais sua existência e função e convidar as pessoas para participarem, pois, é visível que os cidadãos precisam tomar conhecimento sobre esse órgão para que ele funcione de forma plena (Cotta et al., 2011).

Conforme trecho extraído do artigo de Wendhausen e Caponi (2002, p. 1627; Pitta, 1996) "a pouca visibilidade pública das pautas e decisões dos conselhos acaba por impossibilitar que esse órgão seja, de fato, uma 'caixa de ressonância' das demandas sociais". O artigo sete da Lei n. 8.080/90 estabelece a "divulgação de informações quanto ao potencial dos serviços de saúde e a sua utilização pelo usuário" como um princípio para todos os serviços de saúde vinculados ao SUS (Lei n. 8.080, de 19 de setembro de 1990). Retomando as ideias propostas por Cotta et al. (2011, p. 1122) "os conselhos de saúde se tornam um importante elemento para a participação da sociedade na tomada de decisão, e também um mecanismo estratégico para garantia da democratização do poder decisório, ao lado da universalidade e da equidade no SUS".

Todas essas ideias apontam para a importância do Conselho de Saúde em um município e a necessidade de informar a população sobre o órgão. Quanto mais os usuários estiverem familiarizados com o tema, maior a possibilidade de participação e, consequentemente, da garantia de direitos e manutenção de uma democracia representativa.

Além do incentivo a presença nas reuniões, é importante incentivar as manifestações dos participantes. Conforme apontado por Siqueira, Soares, Cruz, Carvalho e Cotta (2020), por vezes os participantes/conselheiros sentem-se intimidados para dar sua opinião por receio de sofrerem prejuízos ou represálias. Em alguns relatos do artigo supracitado também se observa que há uma percepção de desigualdade de poderes, o que causa intimidação e retração das manifestações. Ainda analisando os excertos do artigo utilizado para discussão, observou-se que alguns participantes optam por abster-se das discussões, pois acreditam não ter conhecimento suficiente acerca do assunto. Esse ponto também foi observado nas respostas do questionário base do presente estudo, onde diversos respondentes disseram não participar por não serem da área da saúde e não terem propriedade do assunto.

No entanto, sabe-se que é a população que conhece as suas necessidades e, portanto, suas manifestações têm relevância para as discussões. Com a participação efetiva dos usuários, os ganhos para a saúde são incontáveis, visto que, é possível entender o que a população realmente necessita, possibilitando assim, a criação de políticas públicas mais eficazes. Para Sheedy, MacKinnon, Pitre, Watling e Networks (2008) o envolvimento do cidadão é importante em todas as etapas do desenvolvimento de políticas, visto que auxilia na propagação dos valores e necessidades da população e aumenta a legitimidade das decisões públicas. 


\section{Considerações Finais}

A partir deste estudo pode-se perceber que a população do município estudado não tem engajamento e conhecimento acerca do CMS e quando sabe algo sobre o assunto, as informações são rasas. Com a análise teórica de outros estudos realizados em diferentes regiões do Brasil, percebe-se que esse fato tende a se repetir em outros locais.

Nota-se que as disciplinas da graduação que abordam esse tema são de suma importância para a disseminação da ideia de uma maior participação social, uma vez que informam, incentivam a participação dos estudantes e corroboram com a formação de profissionais mais alinhados com os princípios do SUS. Além disso, deve-se apontar a necessidade de uma maior divulgação, para a população como um todo, do funcionamento do Conselho, sua importância, horários das reuniões e como participar, para que assim prossiga-se para a real democratização das tomadas de decisões na área da saúde. Neste sentido, entende-se que este estudo contribuiu para ampliar o conhecimento da população participante sobre o controle social e, principalmente, para compreender a importância do engajamento de cada munícipe no órgão.

Em consonância com Duarte e Machado (2012), entende-se que a participação está em processo construtivo, assim como o sistema público de saúde do Brasil. A pouco mais de três décadas o país era governado em regime ditatorial e o controle social era uma forma de controle do Estado sobre a população, hoje, ele é tido como o controle da sociedade sobre o Estado (Correia, 2000). Apesar das muitas fragilidades do sistema, "o avanço democrático que experimentamos com sua criação e funcionamento é real" (Duarte \& Machado, 2012, p. 135).

O processo de fortalecimento e popularização do controle social, passa por uma formação de qualidade dos profissionais da saúde, gestores públicos e conselheiros, mas também passa por um processo de informação da população. Desta forma, para que se garanta o pleno funcionamento democrático do CMS, é necessário divulgar e incentivar a participação da população.

Por fim, sugere-se que sejam realizados mais estudos de caráter qualitativo sobre o CMS, investigando sobre o conhecimento e engajamento dos conselheiros do órgão de controle social. Entende-se que, apesar de já existirem estudos com essa linha de investigação, é necessário atualizá-los e aplicá-los em outras regiões do Brasil. Ademais, propõe-se trabalhos com a comunidade, com o objetivo de conscientizar a população e motivar sua participação dentro do CMS.

\section{Agradecimentos}

Aos usuários participantes da enquete e aos demais estudantes da disciplina de Saúde Coletiva da Universidade do Vale do Taquari, semestre dois mil e vinte B.

\section{Referências}

Albuquerque, M. I. N. (2015). Uma revisão sobre as Políticas Públicas de Saúde no Brasil. Recife: https://ares.unasus.gov.br/acervo/html/ARES/3333/1/2saud_socie_polit_public_saud_2016.pdf

Bertolli Filho, C. (2011). História da saúde pública no Brasil (5a ed.). Ática.

Brasil. (1986). Ministério da Saúde. Conselho Nacional de Saúde. $8^{a}$ Conferência Nacional de Saúde: relatório final. http://bvsms.saude.gov.br/bvs/publicacoes/8_conferencia_nacional_saude_relatorio_final.pdf

Brasil. (2005). Ministério da Saúde. O SUS de A a Z: garantindo saúde nos municípios. Brasília: Ministério da Saúde. 344 p.: il. color. - (Série F. Comunicação e Educação em Saúde).

Brasil. (2014). Ministério da Saúde. Para entender o controle social na saúde. Brasília: Ministério da Saúde 178 p. http://bvsms.saude.gov.br/bvs/publicacoes/para_entender_controle_social_saude.pdf

Correia, M. V. C. (2000) Que controle social? Os conselhos de saúde como instrumento. Fiocruz. https://static.scielo.org/scielobooks/qycmp/pdf/correia9788575415221.pdf 
Research, Society and Development, v. 10, n. 3, e32610313458, 2021 (CC BY 4.0) | ISSN 2525-3409 | DOI: http://dx.doi.org/10.33448/rsd-v10i3.13458

Cotta, R. M. M., Cazal, M. M., \& Martins, P. C. (2010). Conselho Municipal de Saúde: (re)pensando a lacuna entre o formato institucional e o espaço de participação social. Ciência \& Saúde Coletiva, 15(5), 2437-2445. 10.1590/S1413-81232010000500018.

Cotta, R. M. M., Martins, P. C., Batista, R. S., Franceschinni, S. C. C., Priore, S. E., \& Mendes, F. F. (2011). O controle social em cena: refletindo sobre a participação popular no contexto dos conselhos de saúde. Physis: Revista de Saúde Coletiva, 21(3), 1121-1137. 10.1590/S0103-73312011000300019.

Duarte, E. B., \& Machado, M. F. A. S. (2012). O exercício do controle social no âmbito do Conselho Municipal de Saúde de Canindé, CE. Saúde e Sociedade, 21(Suppl.1), 126-137. 10.1590/S0104-12902012000500011

Lei $n$. 8.080, de 19 de setembro de 1990. Dispõe sobre as condições para a promoção, proteção e recuperação da saúde, a organização e o funcionamento dos serviços correspondentes e dá outras providências. http://www.planalto.gov.br/ccivil_03/leis/18080.htm

Lei n. 8.142, de 28 de dezembro de 1990. Dispõe sobre a participação da comunidade na gestão do Sistema Único de Saúde (SUS) e sobre as transferências intergovernamentais de recursos financeiros na área da saúde e dá outras providências. http://www.planalto.gov.br/ccivil_03/leis/18142.htm

Paiva, C. H. A., \& Teixeira, L. A. (2014). Reforma sanitária e a criação do Sistema Único de Saúde: notas sobre contextos e autores. História, Ciências, Saúde - Manguinhos, 21(1), 15-35. 10.1590/S0104-59702014000100002

Pereira A.S. et al. (2018). Metodologia da pesquisa científica. UFSM. https://repositorio.ufsm.br/bitstream/handle/1/15824/Lic_Computacao_MetodologiaPesquisa-Cientifica.pdf? sequence $=1$.

Rolim, L. B., Cruz, R. S. B. L. C., \& Sampaio, K. J. A. J. (2013). Participação popular e o controle social como diretriz do SUS: uma revisão narrativa. Saúde em Debate, 37(96), 139-147. 10.1590/S0103-11042013000100016

Sheedy, A., MacKinnon, M. P., Pitre, S., Watling, J., \& Networks, C. P. R. (2008). Handbook on citizen engagement: beyond consultation. Ottawa (CA): Canadian Policy Research Networks.

Siqueira, R. L., Soares, J. B., Cruz, P. S., Carvalho, I. M. M., \& Cotta, R. M. M. (2020). Political representation on the boards of health: empirical and analytical challenges. Research, Society and Development, 9(9), e870997503. https://rsdjournal.org/index.php/rsd/article/view/7503. 10.33448/rsd-v9i9.7503

Turato, E. R. (2005). Métodos qualitativos e quantitativos na área da saúde: definições, diferenças e seus objetos de pesquisa. Revista de Saúde Pública, 39(3), 507-514. 10.1590/S0034-89102005000300025

Wendhausen, A., \& Caponi, S. (2002). O diálogo e a participação em um conselho de saúde em Santa Catarina, Brasil. Cadernos de Saúde Pública, 18(6), 1621-1628. 10.1590/S0102-311X2002000600016 